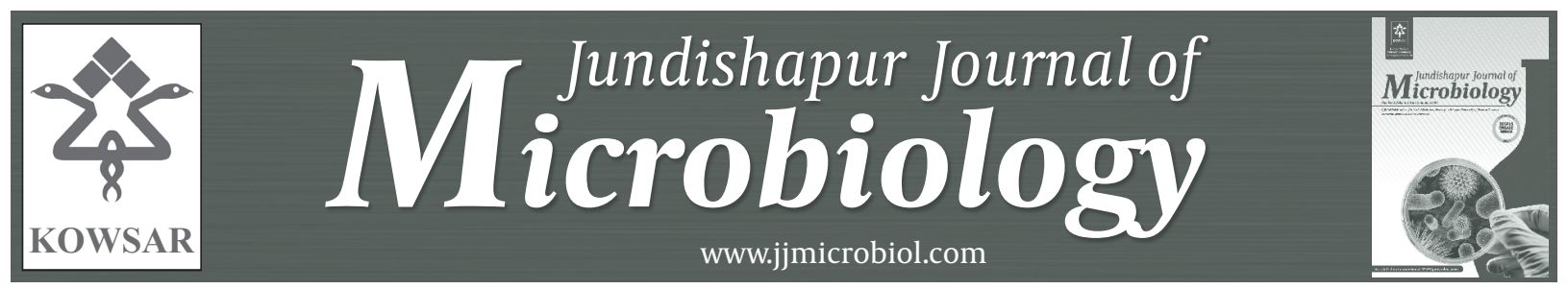

\title{
Evaluation of the Pathogenesis of Pseudomonas aeruginosa's Flagellum Be- fore and After Flagellar Gene Knockdown by Small Interfering RNAs (siRNA)
}

\author{
Abbas Ali Imani Fooladi ${ }^{1}$, Abdoulreza Aghelimansour, Mohammad Reza Nourani ${ }^{2, *}$ \\ ${ }^{1}$ Applied Microbiology Research Center, Baqiyatallah University of Medical Sciences,Tehran, IR Iran \\ ${ }^{2}$ Chemical Injuries Research Center, Baqiyatallah University of Medical Sciences, Tehran, IR Iran \\ ${ }^{*}$ Corresponding author Mohammad Reza Nourani, Chemical Injuries Research Center, Baqiyatallah University of Medical Sciences, Tehran, IR Iran, E-mail: \\ r.nourani@yahoo.com.
}

\begin{abstract}
A B S T R A C T
Background: Pseudomonas aeruginosa possesses a polar flagellum made up of flagellar subunits, which are encoded by fliC gene. Flagella have important roles in the motility, chemotaxis, and establishment of P. aeruginosa in the acute phase of infections. The inhibition of flagellar expression may be a promising therapeutic approach to prevent the pathogenesis. The gene-silencing effect of siRNA may be useful for this strategy.

Objectives: The current study investigated the efficacy of siRNA on the expression of flagellin, because it is an important protein in the initial stages of $P$. aeruginosa infections.

Materials and Methods: The current research designed and synthesized 21 bp siRNA duplexes against P. aeruginosa flagella. Quantitative RT-PCR was performed to determine whether the siRNAs inhibit the expression of the flagellin mRNA in vitro. The efficacy of siRNA was determined by the motility test and in a murine model of hematogenous pulmonary infection.

Results: In quantitative RT-PCR, it was shown that the siRNA significantly inhibited the expression of the flagella mRNA. FilC gene knockdown by the siRNA resulted in a significant decrease in the expression of the flagellar mRNAin the siRNA group as compared with that of the control $(\mathrm{P}<0.05)$. In the motility test,the motility was inhibited in the siRNA group more effectively than in the control group. In the murine infection model, a significant decrease in the number of viable bacteria was detected in the siRNA group when compared with the control ( $7.87 \pm 0.54$ in the former versus $4.69 \pm 0.35 \log \mathrm{cfu} / \mathrm{mL}$ in the latter mean $\pm \mathrm{SD}, \mathrm{P}<0.05$ ).

Conclusions: The development of delivery systems into bacteria with an efficacy compatible to that in human use could be a key for the potential utility of siRNA for the prophylaxis and treatment of P. aeruginosa-induced hematogenous pulmonary infections in humans.
\end{abstract}

Keywords: fliC; siRNA; Pathogenesis; Pulmonary Infections; Murine Model; Pseudomonas aeruginosa

Copyright (@) 2013, Ahvaz Jundishapur University of Medical Sciences; Published by Kowsar Corp.

Article type: Research Article; Received: 02 May 2012, Revised: 20 Jun 2012, Accepted: 03 Jul 2012; DOI:10.5812/jjm.5401

Implication for health policy/practice/research/medical education:

The development of delivery systems into bacteria with an efficacy compatibleto the one in human use could be a key for the potential utility of siRNA for the prophylaxis and treatment of P. aeruginosa-induced hematogenous pulmonary infections in humans.

-Please cite this paper as:

Imani Fooladi AA, Aghelimansour A, Nourani MR. Evaluation of the Pathogenesis of Pseudomonas aeruginosa's Flagellum Before and After Flagellar Gene Knockdown by Small Interfering RNAs (siRNA).Jundishapur J Microbiol. 2013;6(3):IN PRESS. DOI: 10.5812| jjm.5401

Copyright @ 2013, Ahvaz Jundishapur University of Medical Sciences; Published by Kowsar Corp.

This is an Open Access article distributed under the terms of the Creative Commons Attribution License (http://creativecommons.org/licenses/by/3.0), which permits unrestricted use, distribution, and reproduction in any medium, provided the original work is properly cited. 


\section{Background}

Pseudomonas aeruginosa is the most common pathogen responsible for nosocomical and community-acquired infections at various body sites including the lower respiratory tract, urinary tract, cornea, and surgical or burn wounds $(1,2)$. P. aeruginosa has some advantages that help to establish acute or chronic infections under various host conditions (3). One of these advantages is its flagella. Polar flagella provide mobility and chemotaxis, and they also facilitate the adherence to cells and non-living surfaces, which confer the ability to colonize and invade throughout the early phases of infection (4).

Flagella play a critical role in the initial stages of respiratory tract infection, as shown by comparing the virulence of fliC mutants in a neonatal mouse model of pneumonia. There was no mortality in the fliC mutants (2). $P$. aeruginosa flagella are suggested to act in pathogenesis by tethering and adhering to epithelial cells through binding and interaction with epithelial membrane components. However, flagella are also very immunogenic, which renders them susceptible to the host clearance mechanisms and facilitating phagocytic clearance $(5,6)$. Consequently, it is not surprising that flagella have been considered as smart drugtargets for immunotherapy. On the other hand, efforts are underway to develop antimicrobials from classes of compounds for which specific resistance traits do not exist in nature. Therefore, new therapeutic options for $P$. aeruginosa infections can be explored.

RNA-mediated interference (RNAi), originally as an antiviral mechanism, was discovered in plants, and it was subsequently found in Caenorhabditis elegans, Drosophila and vertebrates $(7,8)$. RNAi is an evolutionarily conserved system and a powerful tool to silence gene expression $(9,10)$. To knock-down gene expression by RNAi, two major methods of mRNA silencing exist. The first method utilizes the construction of plasmid DNA that expresses shRNA (short hairpin RNA). The second method is based on siRNA (small interfering RNA), a readily pro- cessed 21 to 22 nucleotide sequence that associates with a multiprotein complex known as the RNA-induced silencing complex (RISC). This ultimately targets homologous mRNA,and destroys it after transfection into the cell, based on complementary base pairing (11). siRNAs are projected to provide an interesting therapeutic advantage for curing genetically dominant disorders,cancers, neurological disorders, and viral and bacterial infections (11).

\section{Objectives}

The current study investigated the inhibitory effects of siRNA on P. aeruginosa flagella in vitro and in vivo.

\section{Materials and Methods}

\subsection{Bacterial Strain}

P. aeruginosa $8821 \mathrm{M}$ was kindly provided by Dr. Oulia (Shahed University, Iran). The bacteria were stored at $-70^{\circ} \mathrm{C}$ in brain heart infusion (BHI) broth (BBL Microbiology Systems, Cockeysville, MD, USA) supplemented with 10\% (v/v) glycerol and 5\% (w/v) skim milk (Yukijirushi Co., Tokyo, Japan) untilused.

\subsection{SiRNAS}

The sequences of siRNA were designed against P. aeruginosa 8821M flagella by established methods (Gene Script software) (12). Sequences of all the tested siRNAs are shown in Table 1. All the RNA oligonucleotides were synthesized by Bionner Co (South Korea). These oligonucleotides were deprotected according to the manufacturer's instructions. The resulting siRNA duplexes were analyzed for completion of duplex formation by gel electrophoresis. Two sets of siRNAswere used for the experiments and siRNA-1 was found more effective than siRNA-2. Therefore, thefurther experiments utilized siRNA-1 $(7,8)$.

\begin{tabular}{|c|c|c|c|}
\hline SiRNA & Sequence & Start & GC, \% \\
\hline SiRNA-1 & & 666 & 47.37 \\
\hline Sense & 5'-ACGUCAAGGUCGACAUGAATT -3' & & \\
\hline Antisense & 5'- UUCAUGUCGACCUUGACGUTT -3' & & \\
\hline SiRNA-2 & & 566 & 57.89 \\
\hline Sense & 5'- GGCACCTACTTCACGGCTA -3' & & \\
\hline Antisense & 5'-UAGCCGUGUUGUAGGUGCC-3' & & \\
\hline siRNA-scramble & & - & 33.3 \\
\hline Control sense & $5^{\prime}$ - ACAGAAGAUAUAGGAGUGATTTT - $3^{-}$ & & \\
\hline ControlAntisense & $5^{\prime}$ - UCACUCCUAUAUCUUCUGUTTTT - $3^{\prime}$ & & \\
\hline
\end{tabular}




\subsection{RNA Extraction and RT-PCR}

P. aeruginosa $8821 \mathrm{M}$ was cultured on a brain heart infusion agar-based (BBL Microbiology Systems) sheep blood agar plate for $24 \mathrm{~h}$ at $37^{\circ} \mathrm{C}$. Bacteria were suspended in endotoxin-free sterile saline and harvested by centrifugation (3000xg, $4^{\circ} \mathrm{C}$ and $10 \mathrm{~min}$ ). The microorganisms were resuspended in cold sterile saline and diluted to 1 $\times 106 \mathrm{cfu} / \mathrm{mL}$, as estimated by turbidometry. P. aeruginosa $8821 \mathrm{M}$ was cultured in trypticase soy broth with the targeted siRNA or with a scrambled siRNA as a control (20, 40 pico mol, and $2 \mu \mathrm{mol}$, respectively).

The siRNAs were added every 20 min (according to the generation time of the bacteria). After $6 \mathrm{~h}$, RNA was extracted from bacteria with a FastRNA Kit-BLUE(BIO 101, Carlsbad, CA, USA), and RT-PCR was performed to determine the level of mRNA according to the kit instructions. Oligonucleotide primers for PCR were designed according to the sequence for $P$. aeruginosa $8821 \mathrm{M}$ flagella (sense, 5'- TGAACGTGGCTACCAAGAACG-3'; antisense, 5'-TCTGCAGTTGCTTCACTTCGC-3'). Rpls gene controls were used as a housekeeping gene (sense, 5'-AAGCGCATGGTCGACAAGA -3'; antisense, 5'- CTGTGCTCTTGCGGTTGTGA -3'). PCR products were separated by electrophoresis through a 1\% agarose gel containing ethidium bromide (Figure 1).

\subsection{Effects of siRNA on Flagella Production}

$P$. aeruginosa $8821 \mathrm{M}$ was cultured with targeted or scrambled siRNA. The siRNAs were added every $20 \mathrm{~min}$. After $4 \mathrm{~h}$, the flagella were assayed by Quantitative Realtime PCR and motility inhibition test.

\subsubsection{Quantitative Real-Time PCR}

For real-time quantitative PCR, 500ng of RT product was used in a whole volume of $15 \mu$ l consisting of $7.5 \mu$ l of SYBR Green Premix 2X (Takara, Shiga, Japan) and 10pM of mix primer in a Rotor-Gene RG 3000 (Corbett Research, Sydney, Australia). Thermocycling conditions were heat-held at $94 \mathrm{C}$ for $1 \mathrm{~min}$, followed by 40 cycles of denaturation at $94 \mathrm{C}$ for $20 \mathrm{sec}$, annealing at $57 \mathrm{C}$ for $30 \mathrm{sec}$, and extension at $72 \mathrm{C}$ for $30 \mathrm{sec}$. The amount of each gene expression depends on the cycle at the threshold (Ct), in which the fluorescence density in the PCR microtube rises above the background and is normalized by rpls gene as the endogenous reference gene. The rpls gene controls were used to standardize the quantification of RNA samples. The rpls gene levels for each condition were measured, and flagella/ rpls ratios were compared ( Figure 1).

The siRNAs were added every 20 min. After $4 \mathrm{~h}$, RNA was extracted from bacteria, and RT-PCR was performed to determine the level of mRNA (A, C). The rpls gene bands for each condition were measured (B) and flagellar/ rpls gene ratios were compared $(\mathrm{C})$. Data are expressed as mean $\pm \operatorname{SD}(n=5)$.

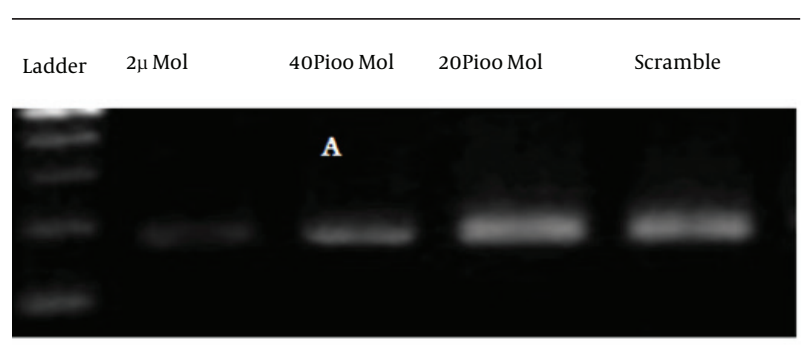

Ladder $\quad 2 \mu \mathrm{Mol} \quad 40 \mathrm{Pioo} \mathrm{Mol} \quad 20 \mathrm{Pioo} \mathrm{Mol} \quad$ Scramble
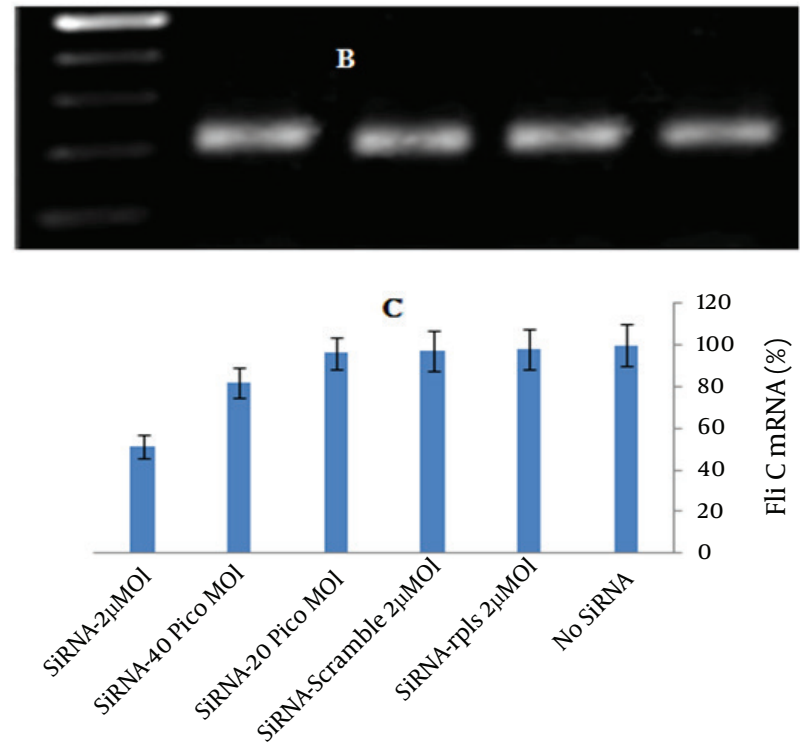

Figure 1. Effects of siRNA Treatment on the Expression of Flagellar mRNA P. aeruginosa Was Cultured With Targeted or Scrambled siRNAs.

\subsubsection{Motility Inhibition Test}

To confirm the effect of siRNA, two plates were filled with $10 \mathrm{ml}$ of motility agar (LB with $0.3 \%$ (w/v) agar, soft agar). Then $25 \mu \mathrm{L}$ of cell suspensions of $P$. aeruginosa strain $8821 \mathrm{M}($ OD600 $=0.2)$, affected and not affected by siRNAin PBS, were inoculated into the central well ( $5 \mathrm{~mm}$ in diameter) of each plate. For each assay, triplicate plates were examined. The plates were incubated at 37C. The mean diameters of bacterial spreading with sharp and less spreading rings were measured after incubation for $24 \mathrm{~h}$ (13) ( Figure 2 ).

\subsection{Dimension of the Integration of 32P-Labelled siRNA by Bacteria}

To confirm the entrance of the siRNA into thebacteria, ${ }^{32} \mathrm{P}$ labeled siRNA was used. ${ }^{32} \mathrm{P}$ siRNA was prepared as described previously (7). Bacteria $\left(1 \times 10^{6} \mathrm{cfu} / \mathrm{mL}\right)$ were incubated with siRNA (30 pmol) for $4 \mathrm{~h}$; then the medium was removed, and the bacteria were washed five times with PBS and centrifugation. The washed bacterial pellets were solubilized by addition of $780 \mathrm{~mL}$ PBS, $10 \mathrm{~mL}$ of $10 \%$ 
SDS, and $10 \mathrm{~mL}$ of chloroform. After centrifugation (3000 $\mathrm{g}, 4 \mathrm{C}$ and $10 \mathrm{~min}$ ), the supernatant was collected as the cytoplasmic fraction. The pellet, which contained the membranes and cell walls, was resuspended in $100 \mathrm{~mL}$ of distilled water. The integrated radioactivity in the different fractions was measured with a scintillation counter. For the control group, bacteria were washed immediately after treatment with radiolabelled siRNA, and cell fractions were prepared as described above (Figure 3).

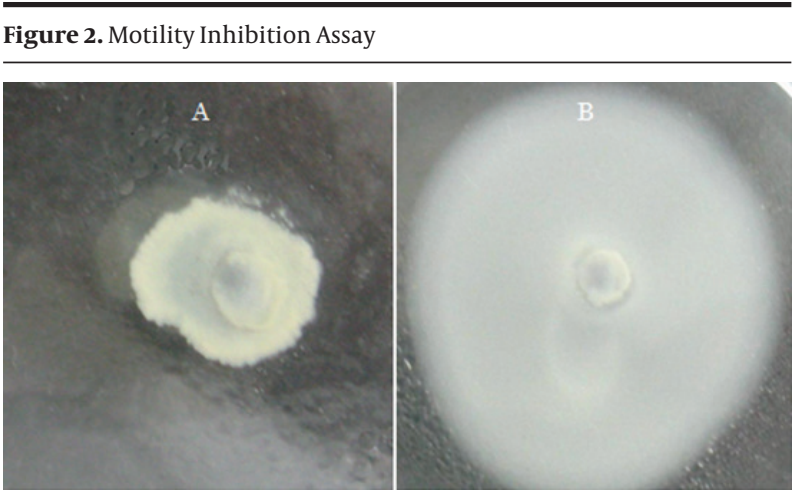

To confirm the effect of siRNA, two plates were filled with $10 \mathrm{ml}$ of motility agar (LB with $0.3 \%(w / v)$ agar, Soft agar) $25 \mu \mathrm{L}$ of a cell suspension of $P$. aeruginosa strain $8821 \mathrm{M}(\mathrm{OD} 600=0.2)$ exposed $(\mathrm{A})$ and no exposed $(\mathrm{B})$ to siRNAin PBS was inoculated into the central well (5 $\mathrm{mm}$ in diameter) of each plate. The motility of the bacteria was inhibited by the specific siRNA (A) as compared them with negative control (B)

\subsection{Laboratory Animals}

Six-week-old pathogen-free male Balb/C mice (25-30 g body weight) were purchased from PasteurInstitute (Tehran, Iran). All animals were housed in a pathogen-free environment at the Laboratory Animal Center. The Ethics Review Committee for Animal Experimentation at our institution approved all of the experimental protocols described in this study in advance. Animal experiments in this study were done in compliance with Baqiyatallah University of Medical Sciences institutional guidelines.

\subsection{Inoculum}

The method of inoculation was described previously $(14,15)$. Bacteria were pre-incubated with siRNA $(2 \mu \mathrm{M})$ or scrambled siRNA $(2 \mu \mathrm{M})$ for $6 \mathrm{~h}$, then they were suspended in endotoxin-free sterile saline and harvested by centrifugation (3000 g, $4^{\circ} \mathrm{C}$, and $10 \mathrm{~min}$ ). The collected microorganisms were resuspended in cold sterile saline and diluted to $2-4 \times 10^{9} \mathrm{cfu} / \mathrm{mL}$, as estimated by turbidimetry. The suspension was warmed to $45^{\circ} \mathrm{C}$, after which 10 $\mathrm{mL}$ of the suspension was mixed with $10 \mathrm{~mL}$ of $4 \%(\mathrm{w} / \mathrm{v})$ molten Noble agar (Difco Laboratories, Detroit, MI, USA) at $45^{\circ} \mathrm{C}$.

The agar-bacterium suspension $(1.0 \mathrm{~mL})$ was placed in a $1.0 \mathrm{~mL}$ syringe, and the suspension was rapidly injected into $49 \mathrm{~mL}$ of rapidly stirred ice-cooled sterile saline using a 26-gauge needle. This resulted in solidification of the agar droplets into beads of $\sim 200 \mu \mathrm{m}$ in diameter. The final concentration of agar was $0.04 \%(w / v)$, and the final number of bacteria was $2-4 \times 10^{7} \mathrm{cfu} / \mathrm{mL}$. Mice were injected in the tail vein with $0.20-0.25 \mathrm{~mL}$ of the bacteria-agar beads per mouse $(10 \mathrm{~mL} / \mathrm{g}$ of body weight). Before the bacteria were embedded in the agar beads, their numbers were verified by inoculating duplicates of serial dilutions onto blood agar plates and counting the cfu after incubation for $48 \mathrm{~h}$ at $37^{\circ} \mathrm{C}(7,8) .4$ groups were used for examination, (bacteria+siRNA, bacteria+ scrambled siRNA, naked siRNA, and bacteria + siRNA injected separately)

\subsection{Bacteriological Examinations}

Each group of animals was sacrificed by cervical dislocation $72 \mathrm{~h}$ after infection. After exsanguination, the lungs were dissected and removed under aseptic conditions. Organs used for bacteriological analyses were homogenized and cultured quantitatively by serial dilution on blood agar plates.

\subsection{Statistical Analysis}

Bacteriological data were expressed as means \pm SD. Differences between groups were examined for statistical significance using an unpaired T-test. A P value of $<0.05$ was considered statistically significant (Figure 4).

\section{Results}

\subsection{Motility, siRNA Treatment, and Expression of Flagellar mRNA}

In the motility test, siRNA inhibited the motility of $P$. aeruginosain siRNA group in comparison with that of the control group (Figure 1). To determine that whether siRNA can control the flagellin production in P. aeruginosa, expression of the flagellar mRNA level was evaluated by RT-PCR after addition of the siRNA to the bacteria. A high dose $(2 \mu \mathrm{M})$ of siRNA significantly inhibited the mRNA expression. In addition, compared with $2 \mu \mathrm{M}$ of the scrambled (control) siRNA, $2 \mu \mathrm{M}$ of siRNA significantly inhibited the production of flagella in P. aeruginosa. It was concluded that mRNA expression was dose-dependently inhibited by siRNAs. Finally, there was an important reduction in flagellar mRNA expression in the siRNA group $(\mathrm{P}<0.05)$.

\subsection{Absorption of Labeled siRNA by Bacteria}

To confirm that the siRNA were transferred to the bacteria, we measured the amount of ${ }^{32} \mathrm{P}$ incorporated into the bacteria following the transfection with ${ }^{32} \mathrm{P}$-labelled siRNA. Intracellular incorporation was determined after washing and eliminating the cell wall and membrane. 
The radioactivity in the cytoplasm was more than 2 -fold higher for the $4 \mathrm{~h}$ pre-treated group than for that of the control group (Figure 3 ).

Figure 3. Absorption of 32P-labelled siRNA Into Bacteria.

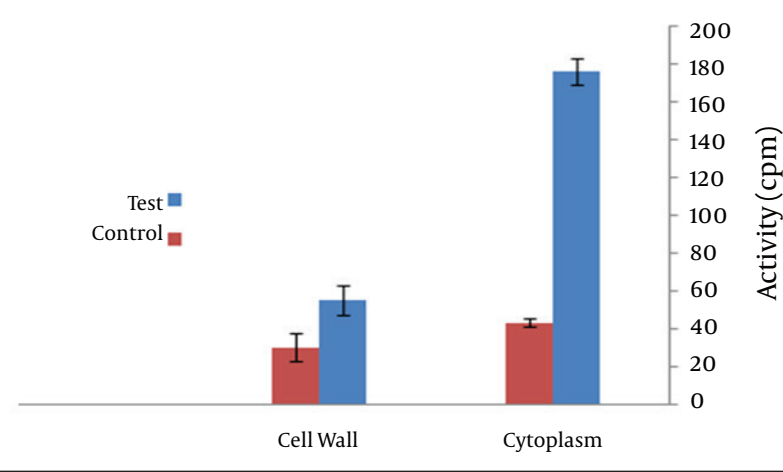

Bacteria were incubated with Bacteria were incubated with 32P-labelled siRNA for $6 \mathrm{~h}$, after which the bacteria were separated into cytoplasmic and membrane/cell wall fractions. The radioactivity in the various fractions is shown for the control bacteria and the bacteria treated for $6 \mathrm{~h}$ with siRNA. The radioactivity in the cytoplasmic fraction of the siRNAtreated sample was more than 3-fold higher than in the control sample.

\subsection{Effects of siRNA in a Murine Model of Hematog- enous Pulmonary Infection}

In a murine model of the hematogenous pulmonary infection, the amount of $P$. aeruginosa was $7.87-0.54$ and $4.69-0.35 \log \mathrm{cfu} / \mathrm{mL}$ (mean $\pm \mathrm{SD}$ ) in control and bacteria+ siRNA groups, respectively, indicating that there was a significant decrease in the number of viable bacteria in the bacteria+ siRNA group $(\mathrm{P}<0.05)$. There was no such significant difference in other groups when compared with control (Figure 4).

Figure 4. Effects ofsiRNA in a Murine Model of Hematogenous Pulmonary Infection

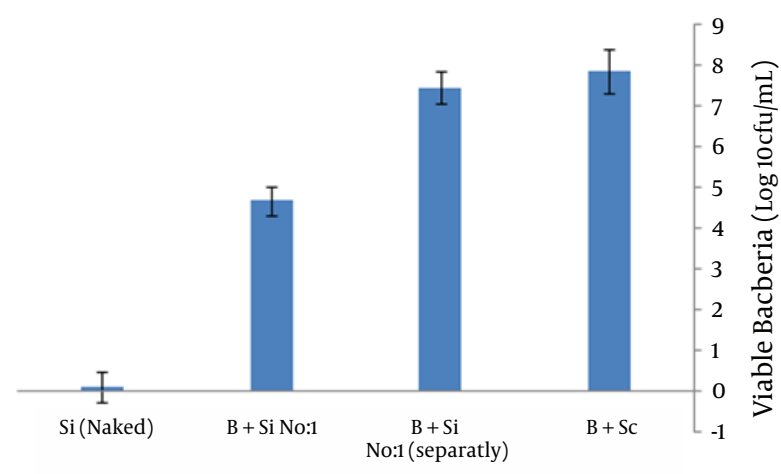

The number of viable bacteria in The number of viable bacteria in the lung from mice sacrificed after 3 days of infection was significantly fewer in the siRNA-1 group than in the scrambled siRNA group. Bacteriological examinations were performed three times without significant differences among them. $\mathrm{B}=$ Bacteria, $\mathrm{Si}=\mathrm{SiRNA}, \mathrm{Sc}=\mathrm{Scramble})\left({ }^{*} \mathrm{p}<0.05\right)$

\section{Discussion}

The current report indicated that (i) siRNAs can potently inhibit $P$. aeruginosa flagellin production in vitro, and that (ii) the number of viable bacteria was significantly decreased by pre-treatment with siRNA. These findings have important implications for the use of siRNA for prophylaxis and treatment of $P$. aeruginosa-induced hematogenous pulmonary infection. This study is the first report on the importance of siRNA against $P$. aeruginosa. The present study examined the effect of siRNA against a pathogenic factor, because the suppression of pathogenic factors is significant for inhibition of infections (16).

The current study results suggest that siRNA may be a therapeutic choice in addition to the other therapeutic methods against infection by $P$. aeruginosavia inhibition of flagellin production. In particular, it was found that siRNA reduced the motility of bacteria (flagella) and the amount of felagellin mRNA in vitro and considerably lowered the number of viable bacteria in vivo. Therefore, siRNA against flagella may be effective in the treatment of $P$. aeruginosa-induced hematogenous pulmonary infections.

However, the inhibition efficacy of the mRNA expression of $P$. aeruginosa flagellin by siRNA was only approximately $45 \%$ compared with the control. Therefore, various devices, to increase the efficacy, are necessary for clinical use, including employment of other vectors such as liposomes for better transfection efficacy. In this regard, lectin-facilitated liposomes, (17), which may allow targeting of specific cell types, may be particularly useful. Since the number of viable bacteria was significantly lower in the siRNA pre-treated group than in the control group, the injection of naked siRNA into the tail vein of mice was tested, resulting in no effect. Therefore, for in vivo delivery, it may be useful to deliver the siRNA in a cationic liposome (18). It is reported that siRNA can be delivered into the lung by rapid intravenous injection of a large volume of siRNA in PBS (19), but, in the current studyexperiments,siRNA was used to target bacteria rather than human cells. The development of delivery systems into bacteria with an efficacy compatible to the onein human use could be a key for the potential utility of siRNA for the prophylaxis and treatment of $P$. aeruginosa-induced hematogenous pulmonary infections in humans. Future studies are needed to genetically screen and identify new siRNA-target genes and to use this siRNA as a flagella-siRNA complementary strand.

\section{Acknowledgements}

The authors wish to thank Dr. Barbara Lee Smith Pierce (University of Maryland University College Scientific and Medical Editing Baltimore, USA) for editorial work in the preparation of this manuscript. 


\section{Financial Disclosure}

The authors declare no financial disclosure.

\section{Funding/Support}

This work was supported by the grants from the Chemical Injury Research Center (CIRC), Baqiyatallah University of Medical Sciences, Tehran, Iran.

\section{Authours' Contribution}

None declared.

\section{References}

1. Driscoll JA, Brody SL, Kollef MH. The epidemiology, pathogenesis and treatment of Pseudomonas aeruginosa infections. Drugs. 2007;67(3):351-68

2. Feldman M, Bryan R, Rajan S, Scheffler L, Brunnert S, Tang H, et al. Role of flagella in pathogenesis of Pseudomonas aeruginosa pulmonary infection. Infect Immun. 1998;66(1):43-51

3. Doring G, Pier GB. Vaccines and immunotherapy against Pseudomonas aeruginosa. Vaccine. 2008;26(8):1011-24

4. Spangenberg C, Heuer T, Burger C, Tummler B. Genetic diversity of flagellins of Pseudomonas aeruginosa. FEBS Lett. 1996;396(23):213-7

5. Arora SK, Ritchings BW, Almira EC, Lory S, Ramphal R. Cloning and characterization of Pseudomonas aeruginosa fliF, necessary for flagellar assembly and bacterial adherence to mucin. Infect Immun.1996;64(6):2130-6

6. Simpson DA, Ramphal R, Lory S. Genetic analysis of Pseudomonas aeruginosa adherence: distinct genetic loci control attachment to epithelial cells and mucins. Infect Immun.1992;60(9):3771-9

7. Yanagihara K, Tashiro M, Fukuda Y, Ohno H, Higashiyama Y, Miyazaki Y, et al. Effects of short interfering RNA against methicillin-resistant Staphylococcus aureus coagulase in vitro and in vivo. J Antimicrob Chemother. 2006;57(1):122-6

8. Fire A, Xu S, Montgomery MK, Kostas SA, Driver SE, Mello CC. Potent and specific genetic interference by double-stranded RNA in Caenorhabditis elegans. Nature. 1998;391(6669):806-11

9. Cerutti H. RNA interference: traveling in the cell and gaining functions? Trends Genet. 2003;19(1):39-46

10. Lavery KS, King TH. Antisense and RNAi: powerful tools in drug target discovery and validation. Curr Opin Drug Discov Devel. 2003;6(4):561-9

11. Ryther RC, Flynt AS, Phillips JA, 3rd, Patton JG. siRNA therapeutics: big potential from small RNAs. Gene Ther. 2005;12(1):5-11

12. Tuschl T, Zamore PD, Lehmann R, Bartel DP, Sharp PA. Targeted mRNA degradation by double-stranded RNA in vitro. Genes Dev. 1999;13(24):3191-7

13. Brett PJ, Mah DC, Woods DE. Isolation and characterization of Pseudomonas pseudomallei flagellin proteins. Infect Immun. 1994;62(5):1914-9

14. Yanagihara K, Cheng PW. Lectin enhancement of the lipofection efficiency in human lung carcinoma cells. Biochim Biophys Acta. 1999;1472(1-2):25-33

15. Sambrook J Russell DW. Molecular Cloning A Laboratory Manual Cold Spring Harbor: Cold Spring Harbor Laboratory Press. 2001.

16. Sawa T, Yahr TL, Ohara M, Kurahashi K, Gropper MA, Wiener-Kronish JP, et al. Active and passive immunization with the Pseudomonas $\mathrm{V}$ antigen protects against type III intoxication and lung injury. Nat Med.1999;5(4):392-8

17. Yanagihara K, Kaneko Y, Sawai T, Miyazaki Y, Tsukamoto K, Hi rakata Y, et al. Efficacy of linezolid against methicillin-resistant or vancomycin-insensitive Staphylococcus aureus in a model of hematogenous pulmonary infection. Antimicrob Agents Chemoth er. 2002;46(10):3288-91

18. Sorensen DR, Leirdal M, Sioud M. Gene silencing by systemic delivery of synthetic siRNAs in adult mice. $J \mathrm{Mol} \mathrm{Biol.}$ 2003;327(4):761-6

19. Zhang X, Shan P, Jiang D, Noble PW, Abraham NG, Kappas A, et al. Small interfering RNA targeting heme oxygenase-1 enhances ischemia-reperfusion-induced lung apoptosis. $J$ Biol Chem. 2004;279(11):10677-84 